\title{
Multinational Comparisons of Health Systems Data, 2014
}

Chloe Anderson The Commonwealth Fund

November 2014 


\section{Health Care Spending}


Average Health Care Spending per Capita, 1980-2012

Adjusted for Differences in Cost of Living

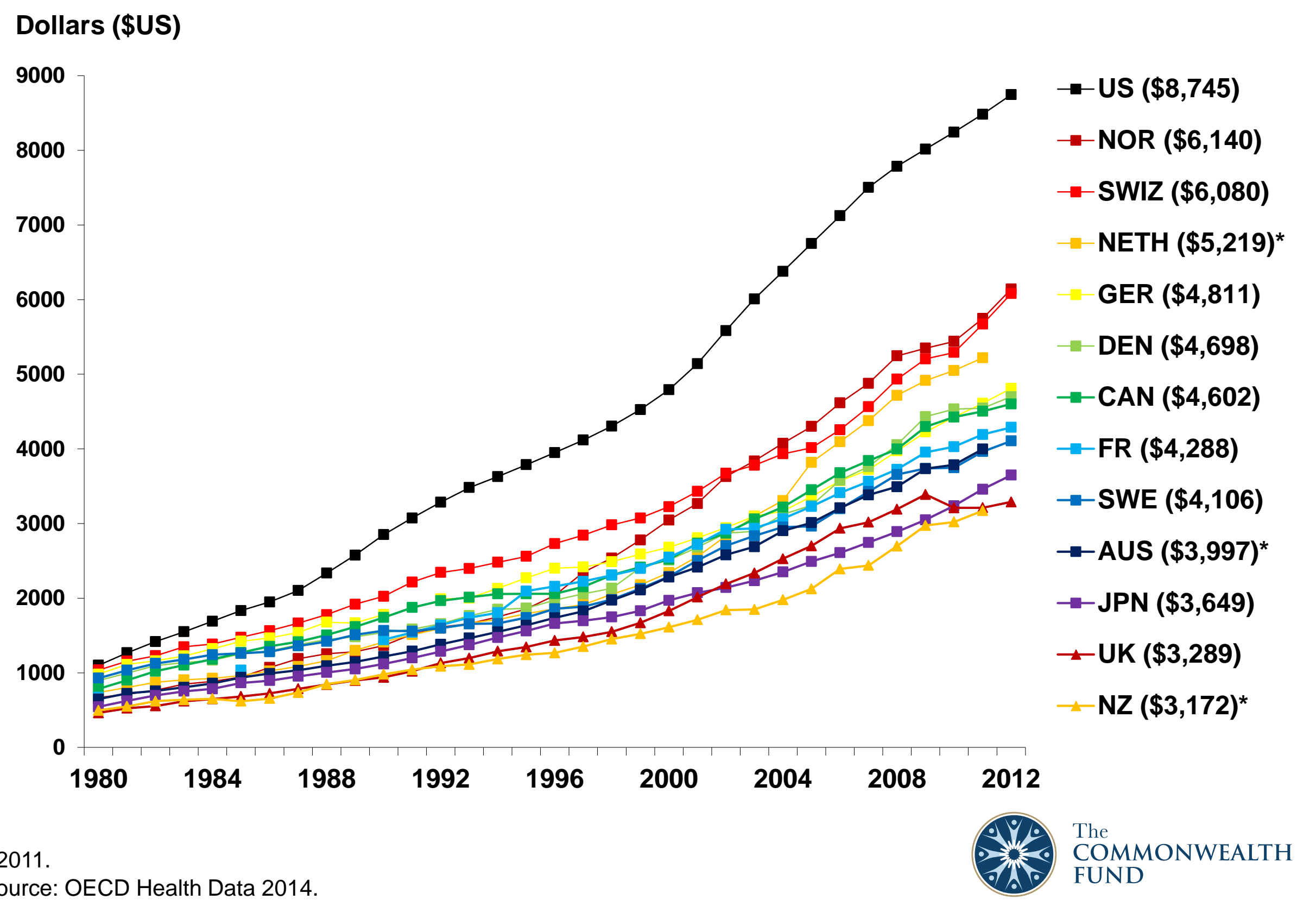




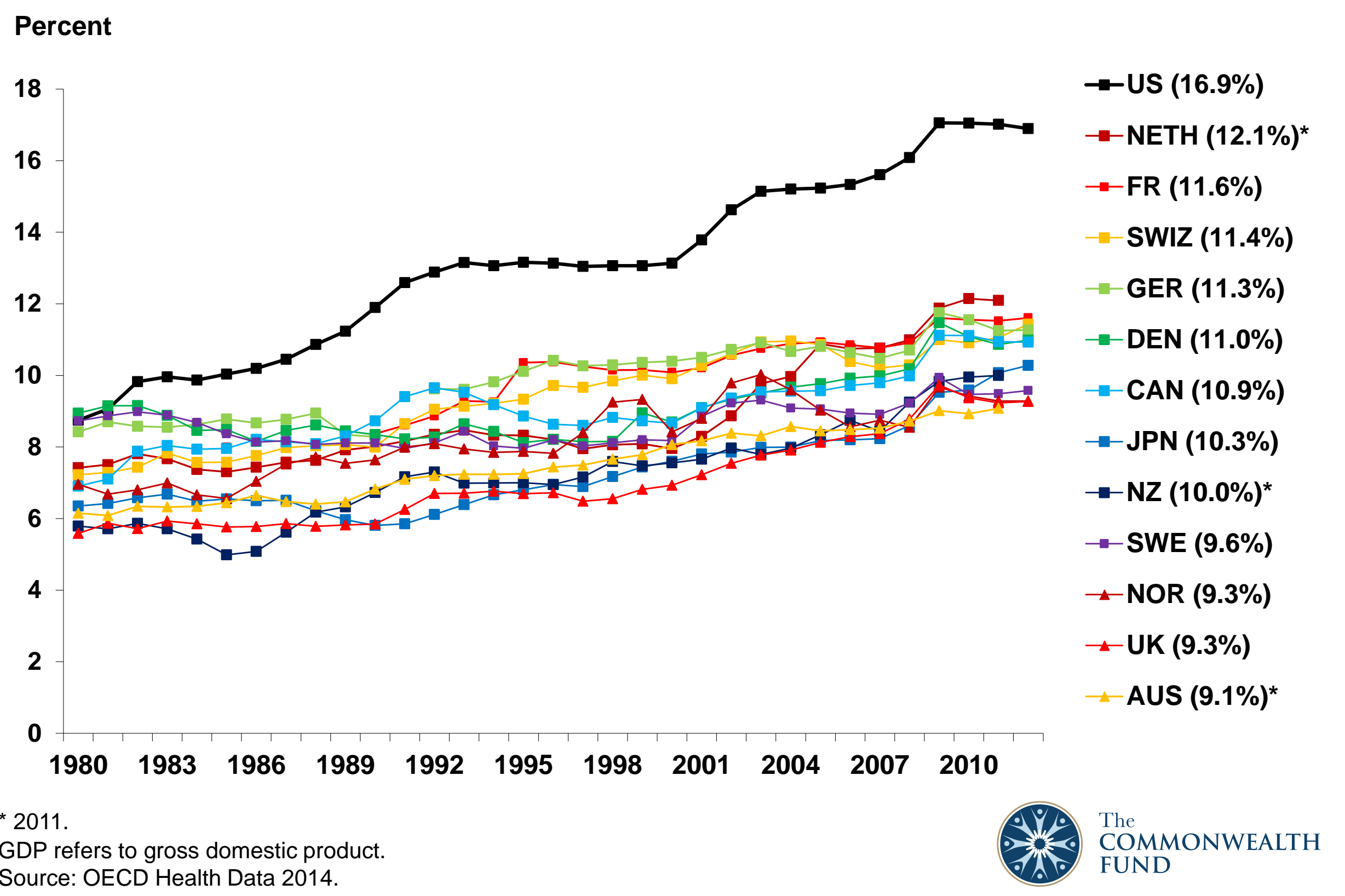


Health Care Spending per Capita by Source of Funding, 2012

Adjusted for Differences in Cost of Living

Dollars (\$US)

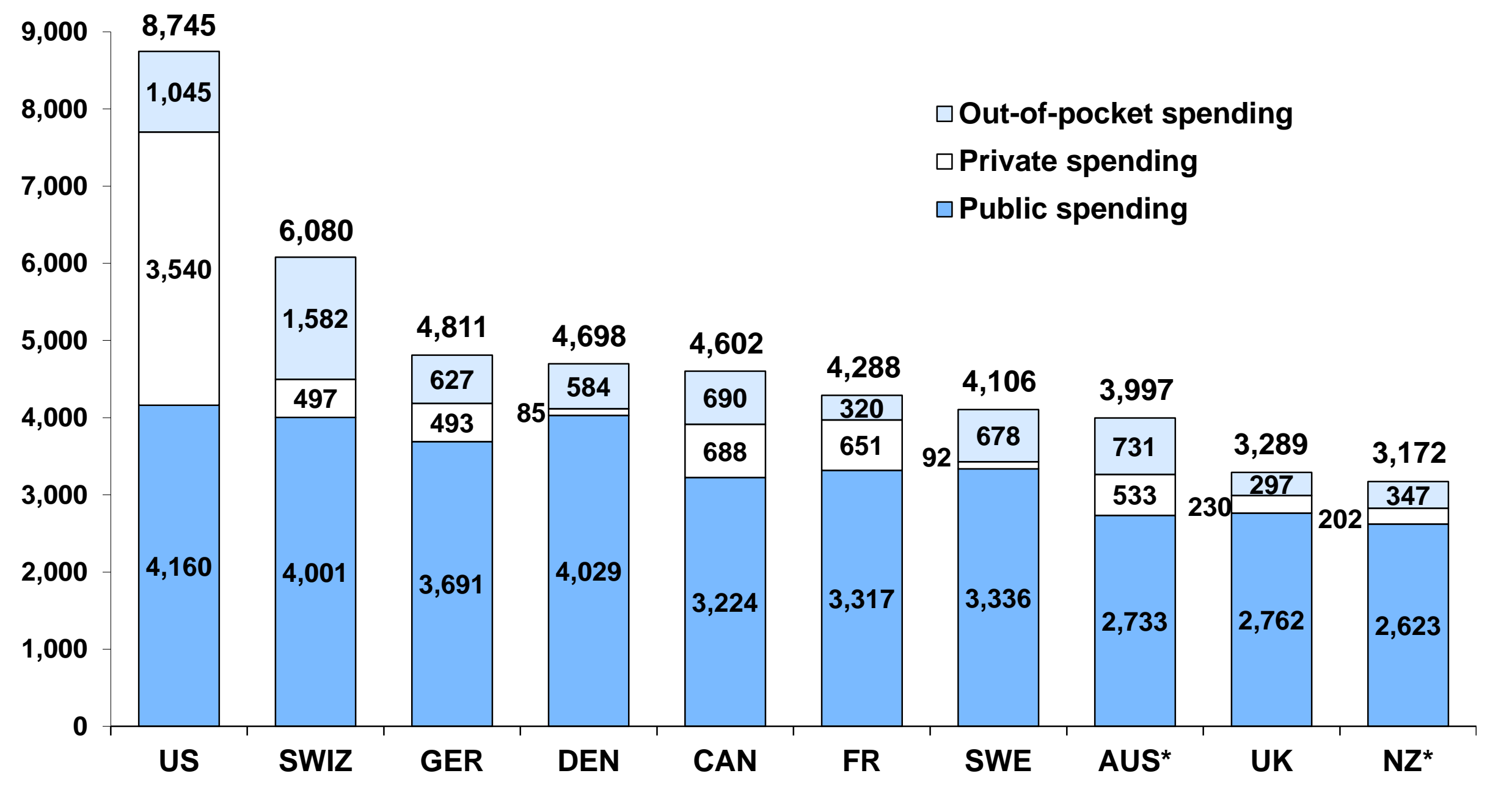


Adjusted for Differences in Cost of Living

Dollars (\$US)

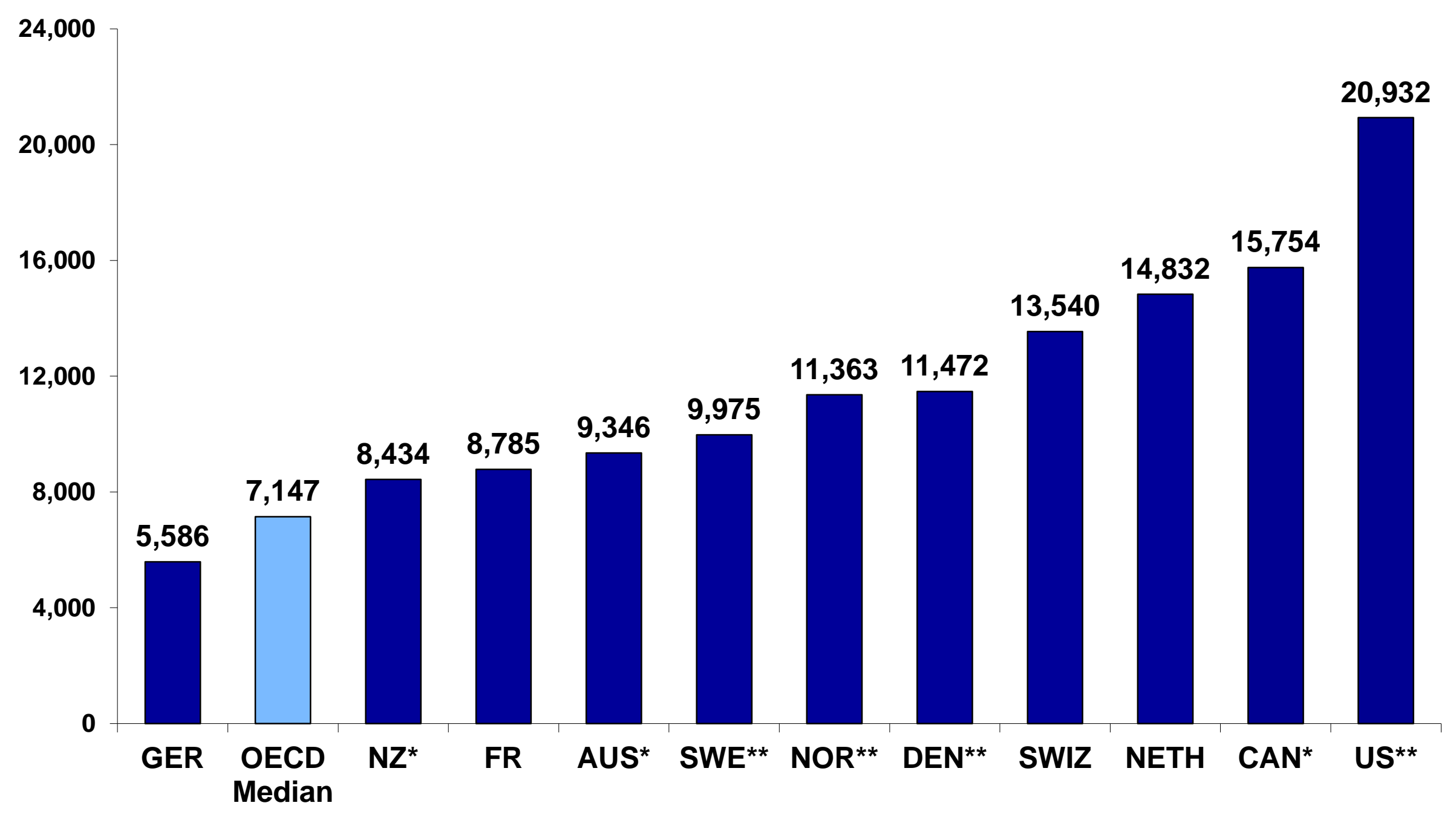


Adjusted for Differences in Cost of Living

Dollars (\$US)

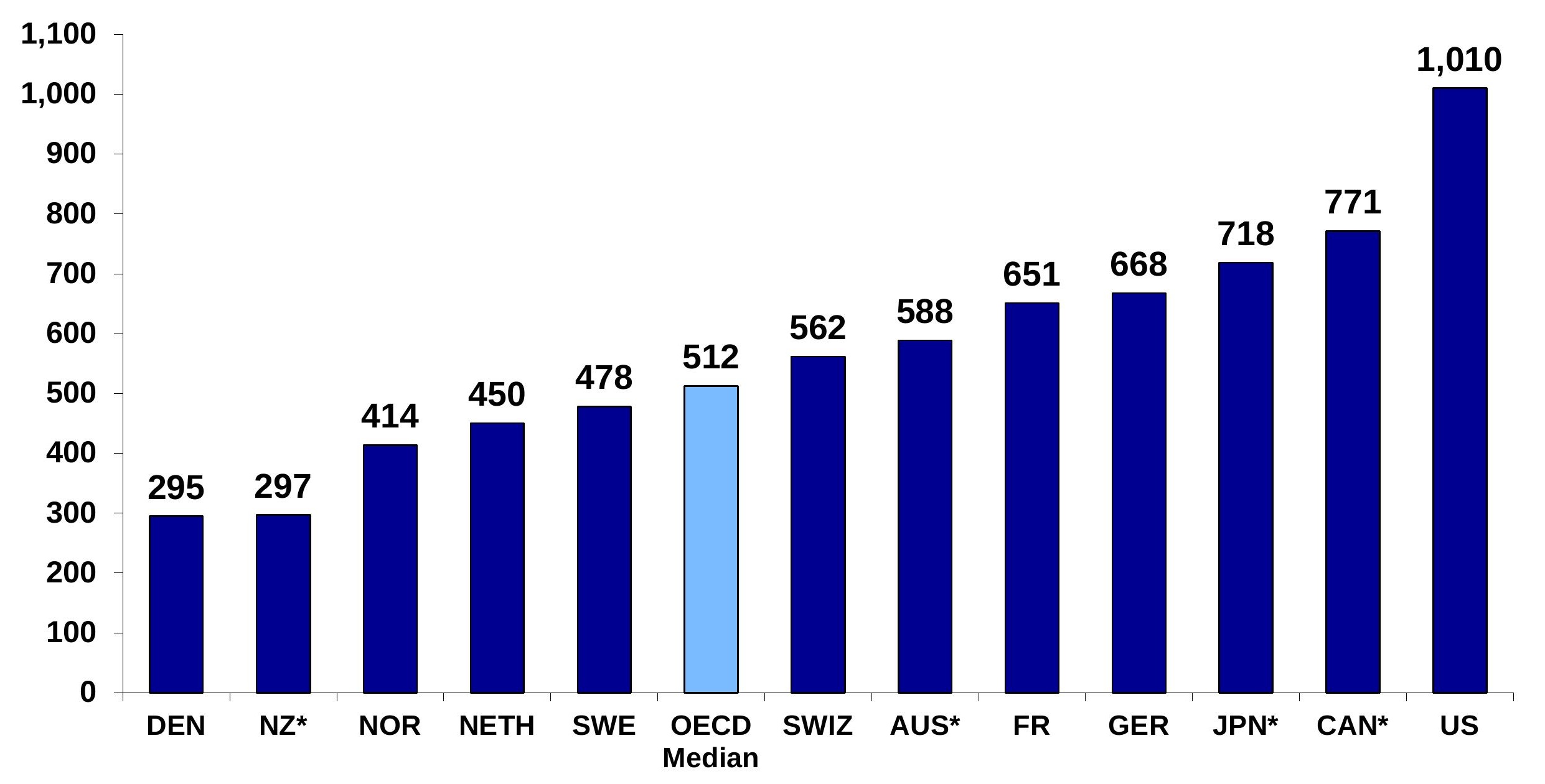


Spending on Health Insurance Administration per Capita, 2012

Adjusted for Differences in Cost of Living

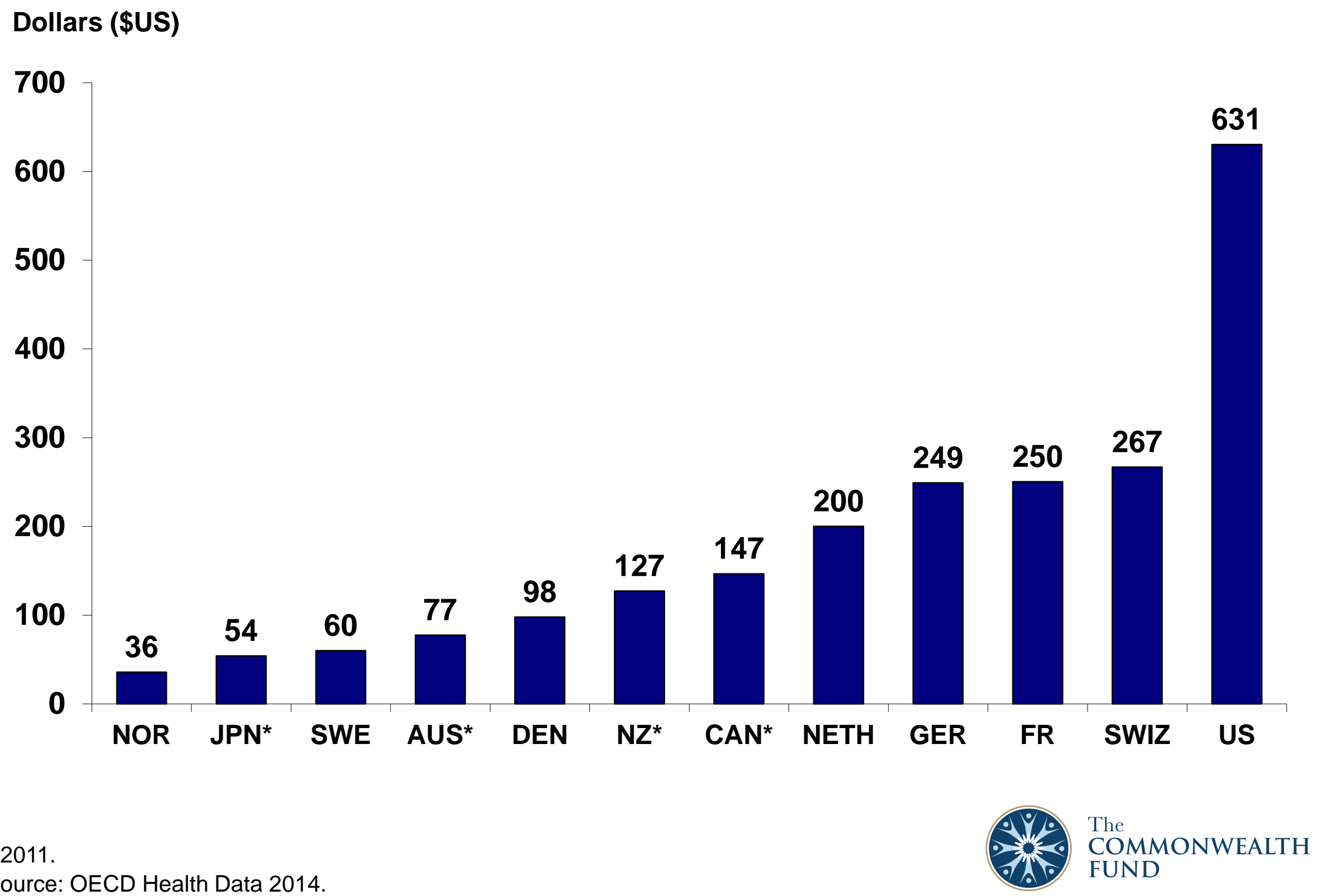




\section{Health Care Supply and Utilization}




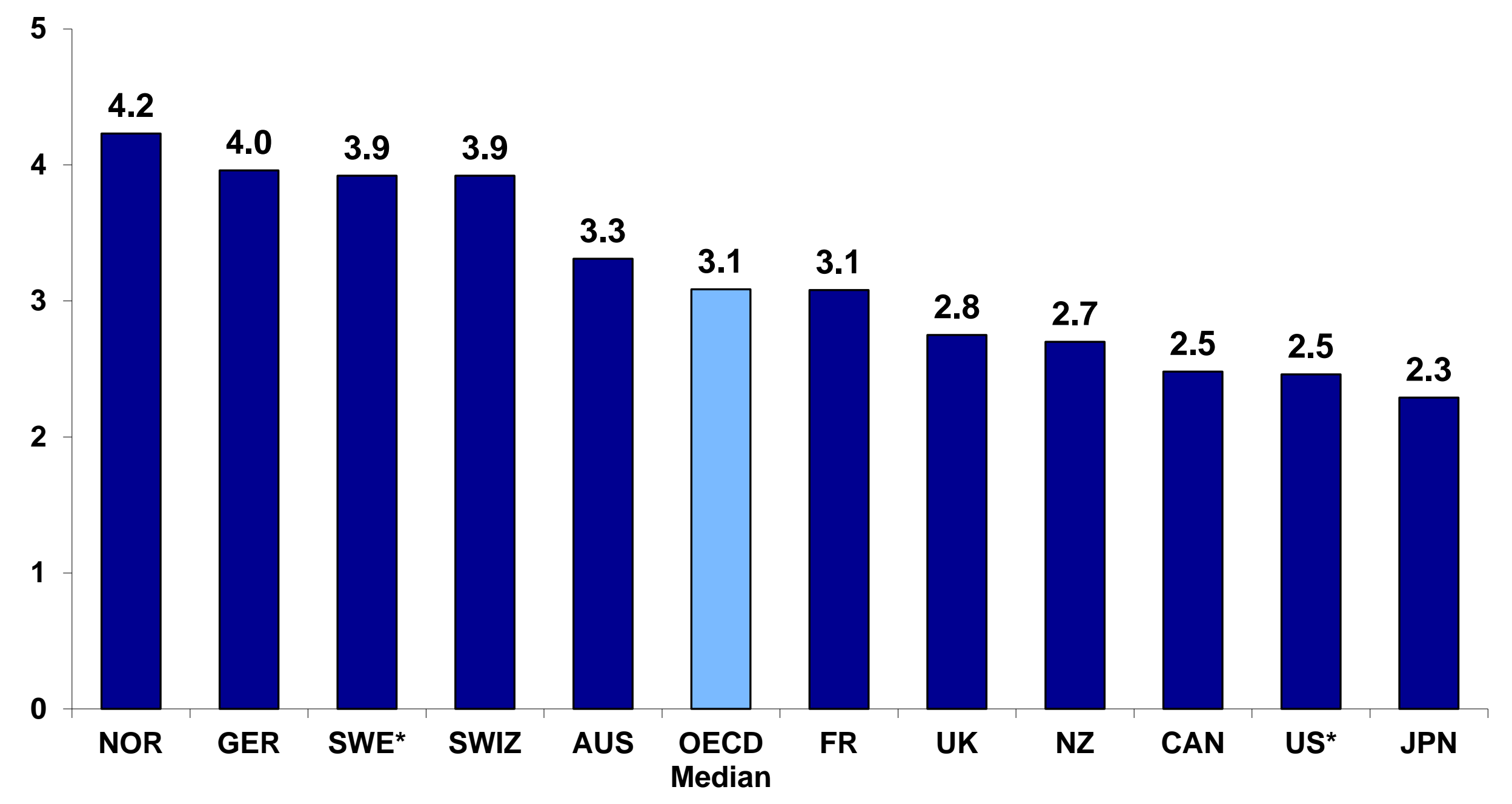


Magnetic Resonance Imaging (MRI) Machines per Million Population, 2012

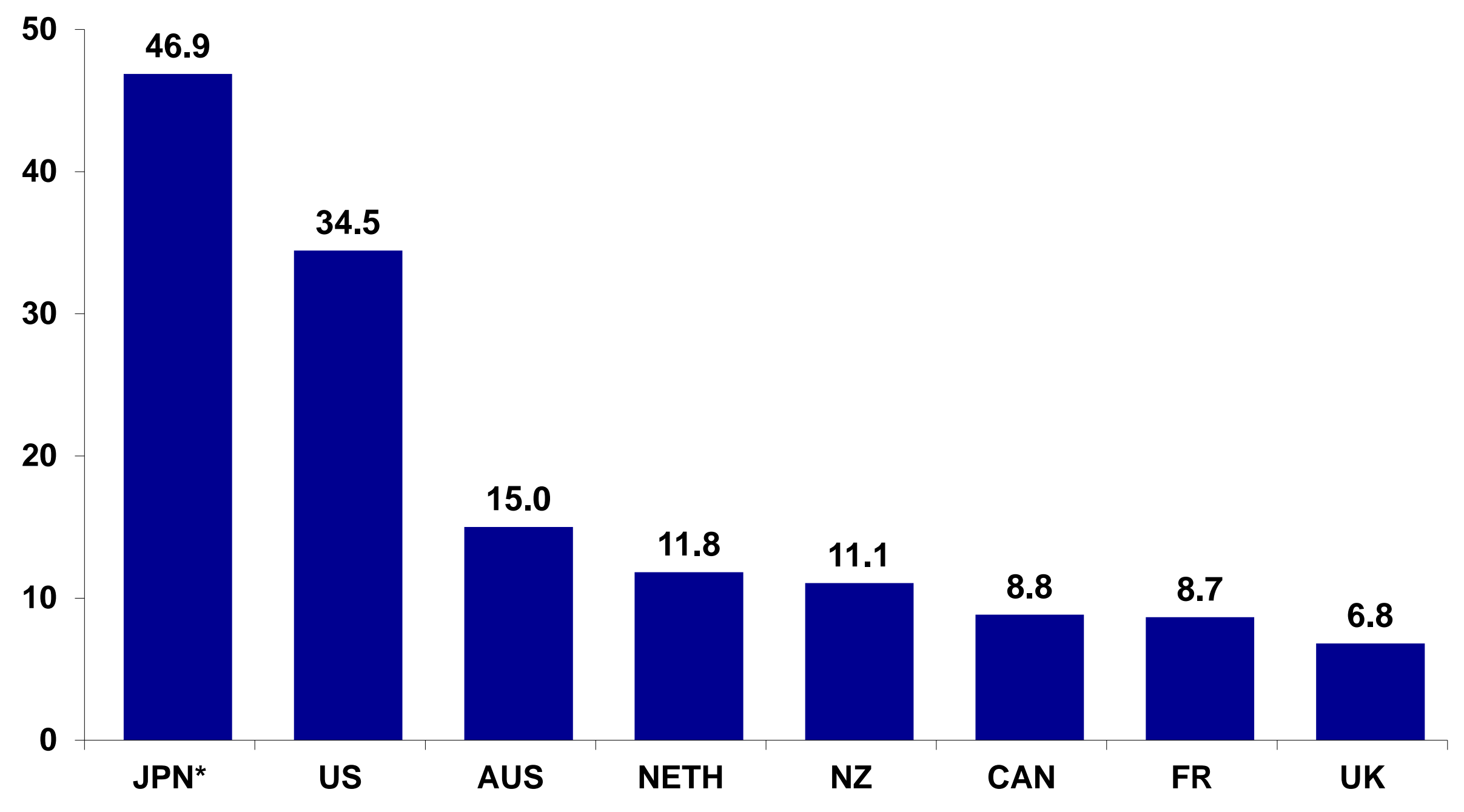


Hospital Discharges per 1,000 Population, 2012

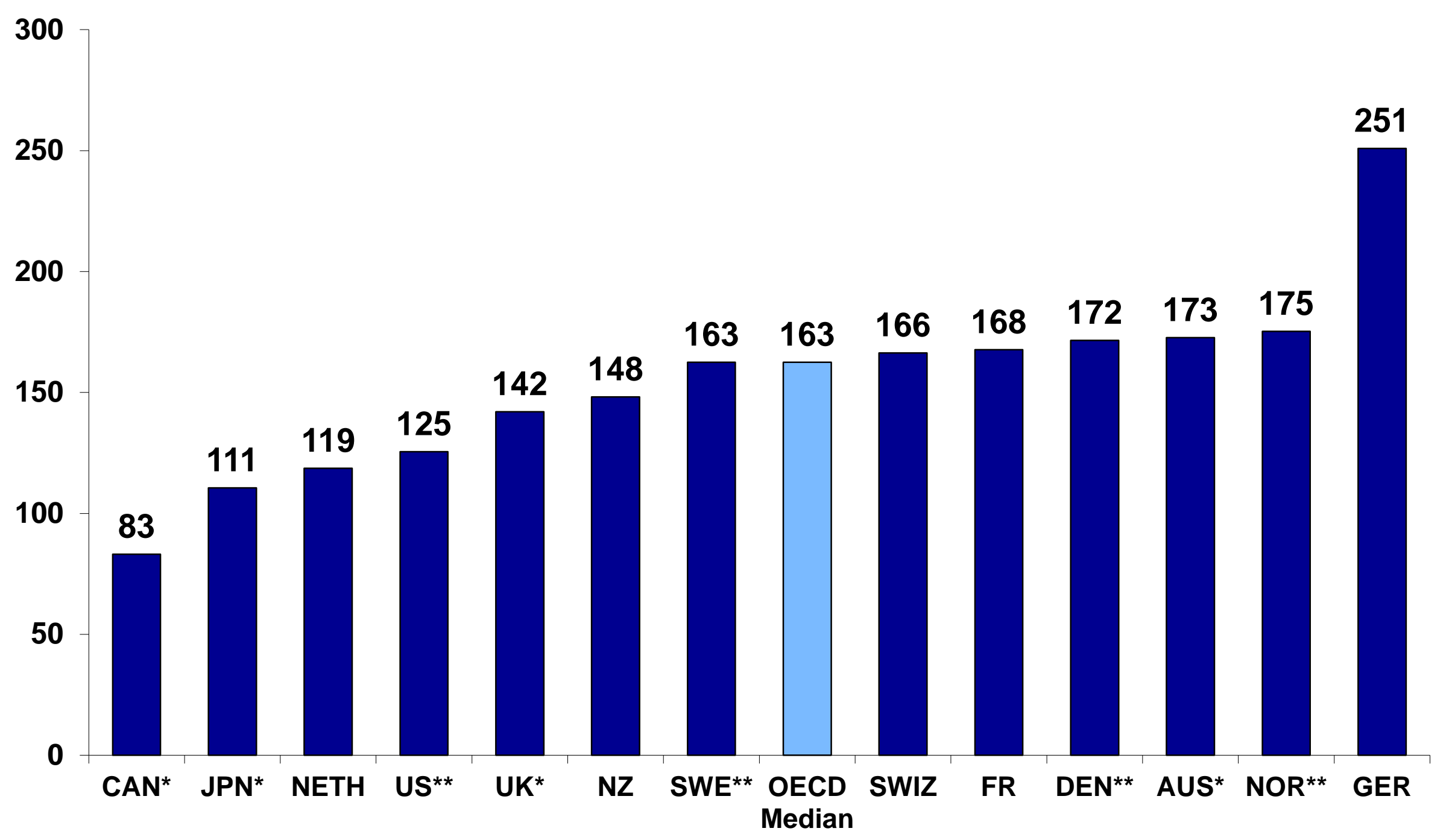




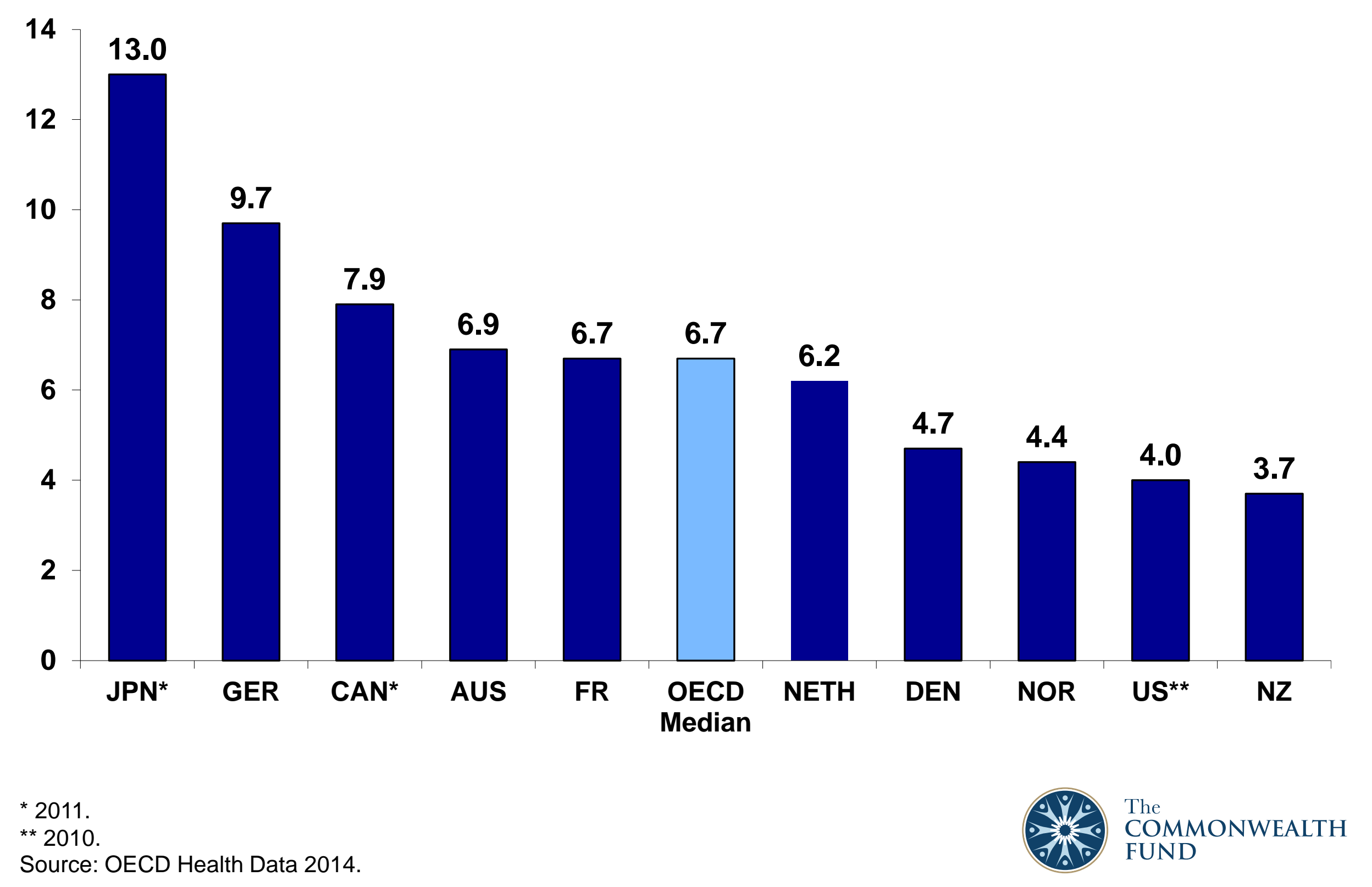




\section{Hip Replacement}

\section{Inpatient Cases per 100,000 Population, 2012}

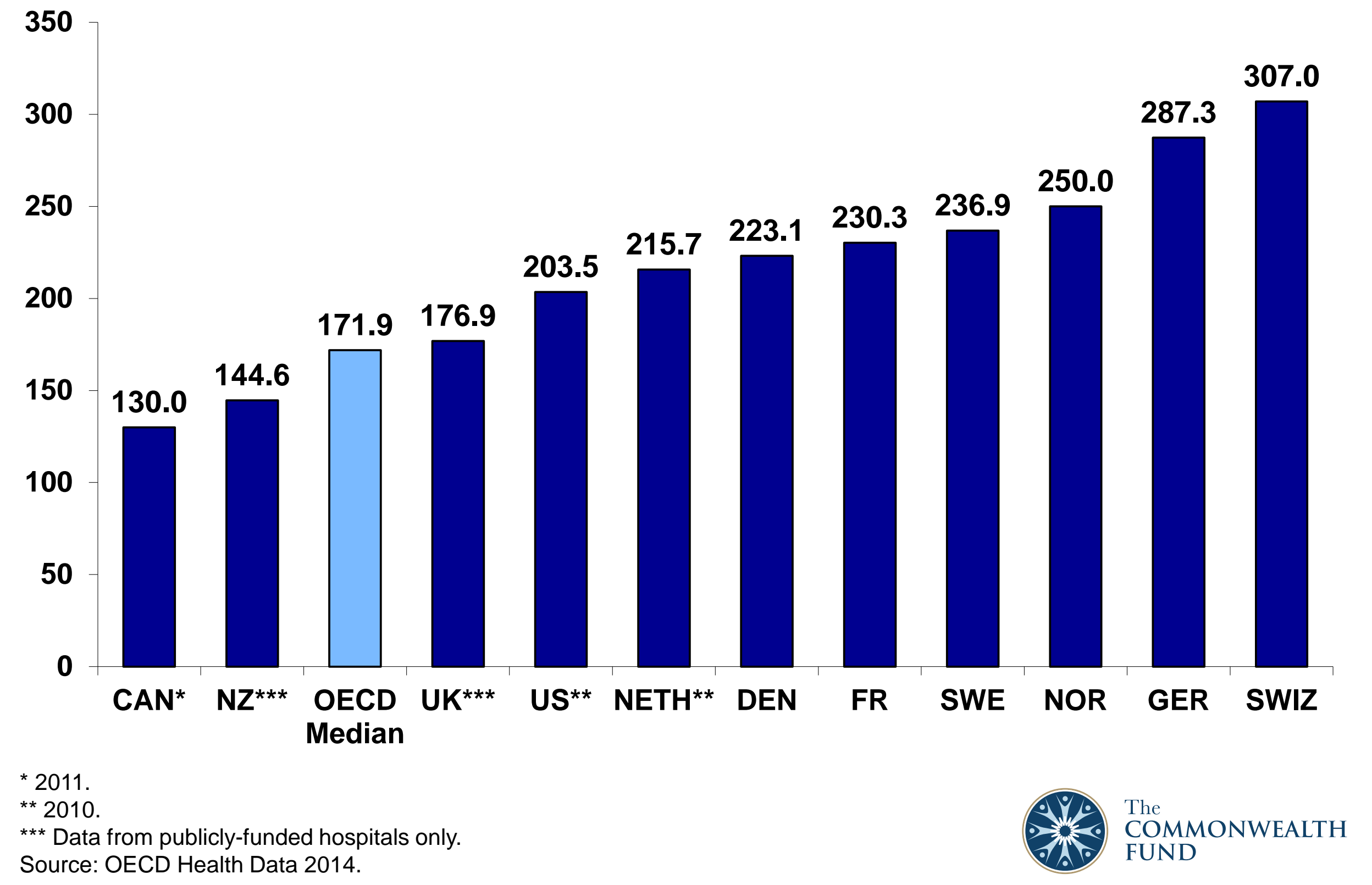




\section{Health Promotion and Disease Prevention}




\section{Cervical Cancer Screening Rates, 2012}

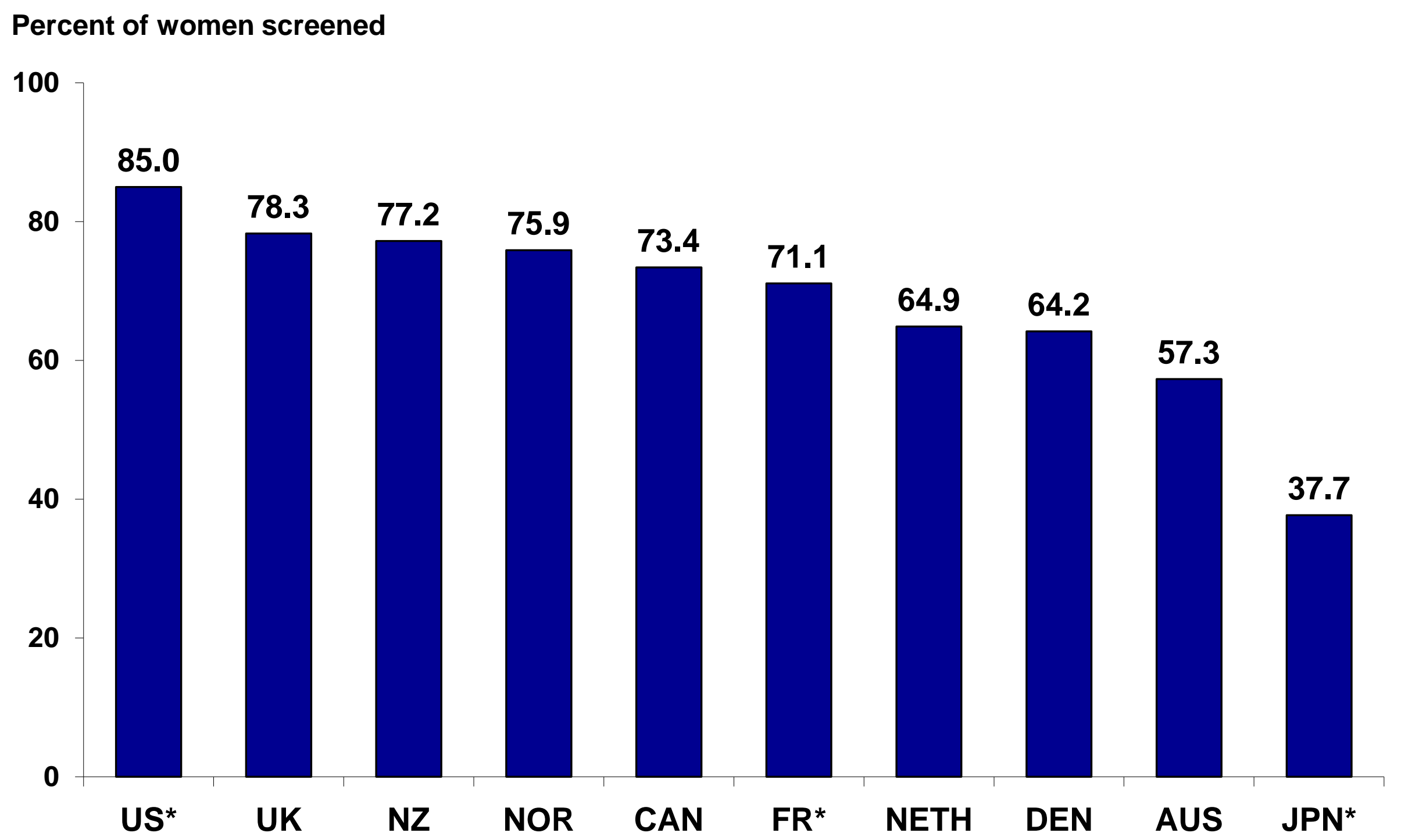

Note: UK, NZ, NOR, DEN, and AUS based on program data; all other countries based on survey data. 
Flu Immunization Among Adults Age 65 or Older, 2012

\section{Percent}

100

$80-75.5$

$\begin{array}{lll}66.9 & 64.3 & 64.1\end{array}$

60

$64.3 \quad 64.1$

40

0

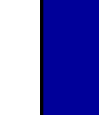

20

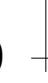

UK

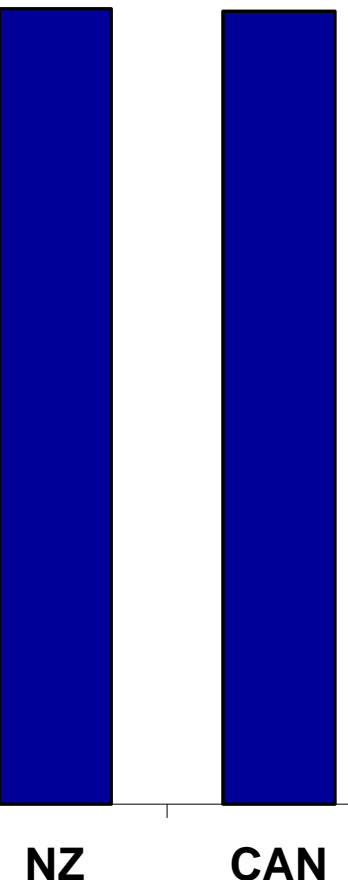

53.1

51.6

50.0

$\square \quad 46.0$

11.4

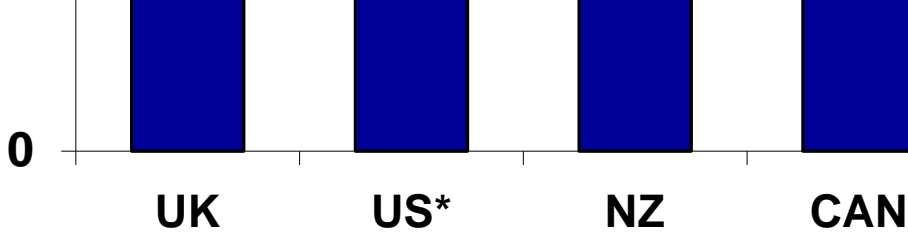

* 2011.

** 2010.

Source: OECD Health Data 2014. 


\section{Percent}

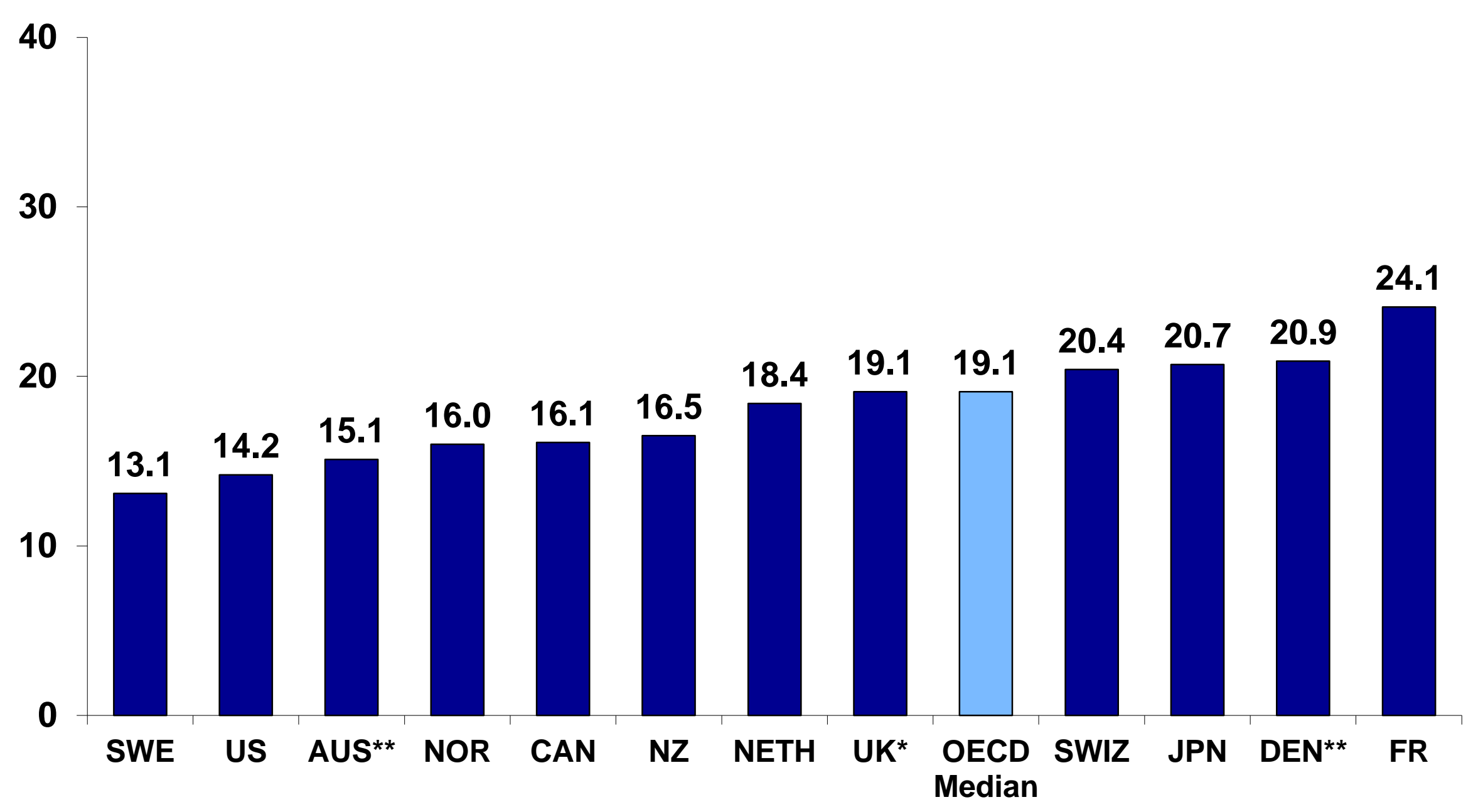




\section{Quality and Patient Safety}




\section{Mortality Amenable to Health Care}

\section{Deaths per 100,000 population*}

150

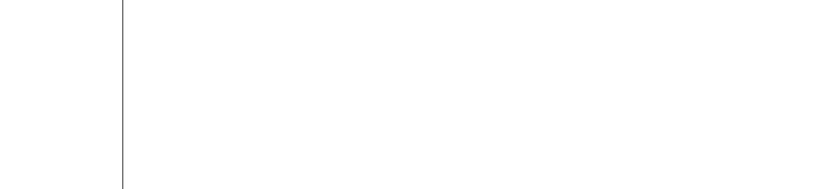

100

50

0

10 $\square$ 1997-98

-2006-07

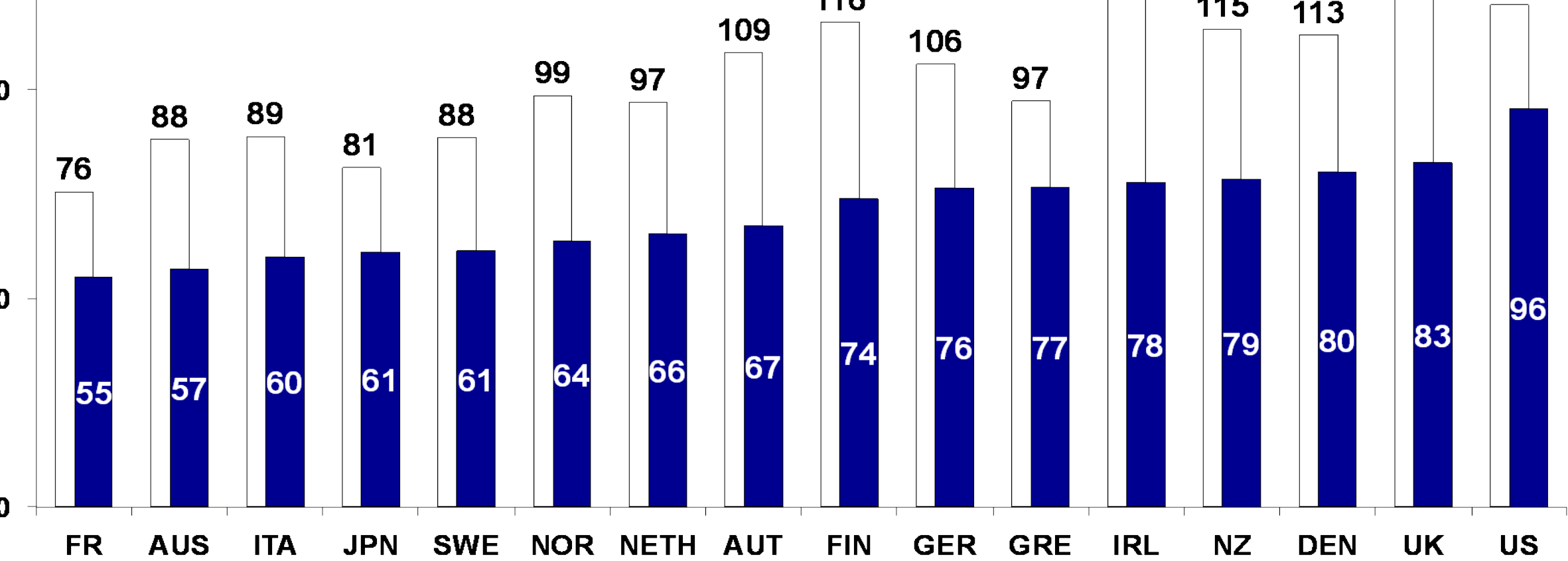

* Countries' age-standardized death rates before age 75; including ischemic heart disease, diabetes, stroke, and bacterial infections. Analysis of World Health Organization mortality files and CDC mortality data for U.S.

Source: Adapted from E. Nolte and M. McKee, "Variations in Amenable Mortality-Trends in 16 High-Income Nations," Health Policy, published online Sept. 12, 2011. 


\section{Breast Cancer Five-Year Relative Survival Rate, 2007-2012}

\section{(or nearest period)}

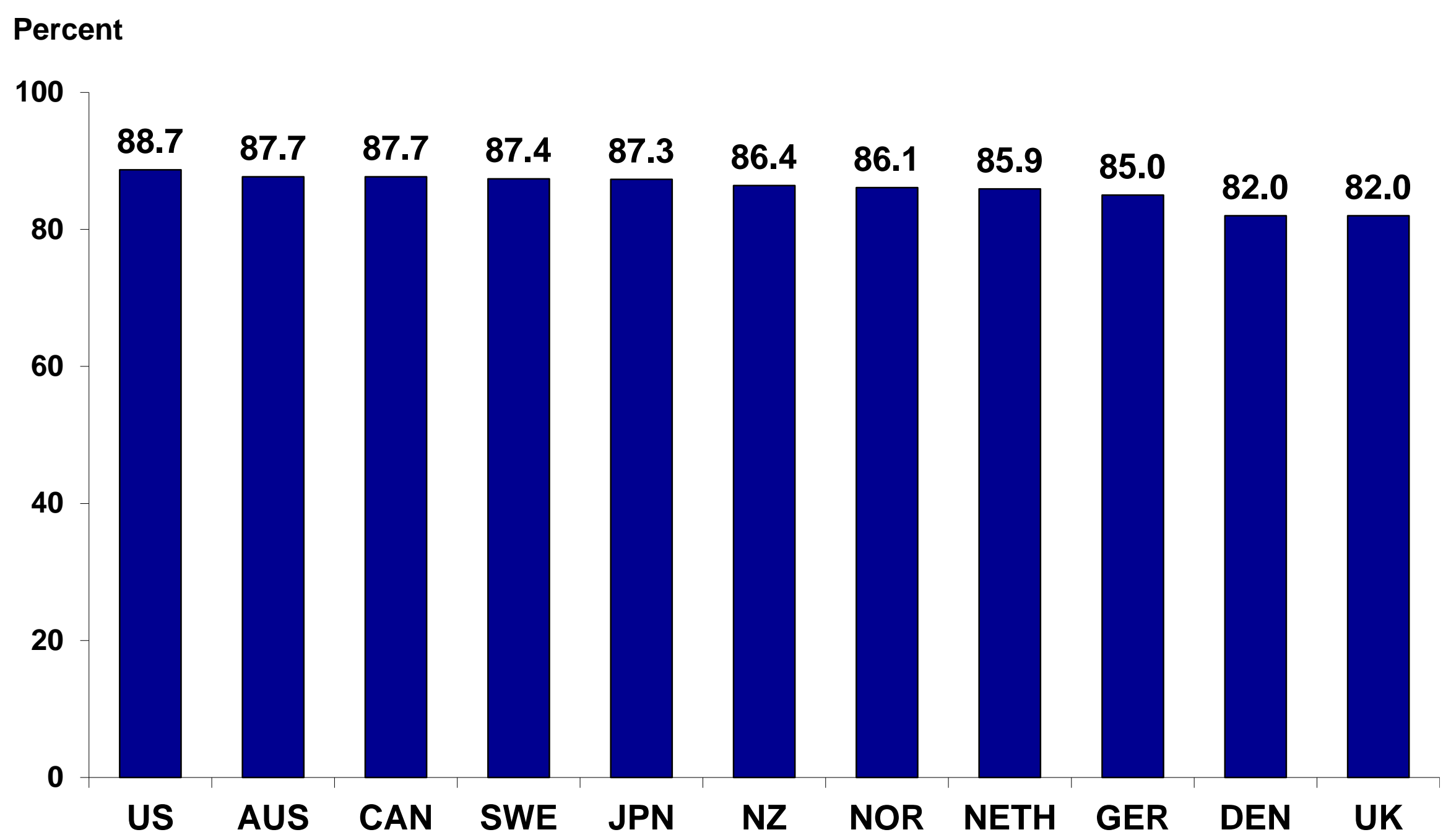

Note: UK and SWE data are from 2007-2012; NZ, NOR, NET, and DEN data are from 2006-2011; AUS data are from 2005-2010; US and GER data are from 2004-2009; CAN data are from 2003-2008; JPN data are from 2000-2005. 


\section{per 100,000 Population, 2011}

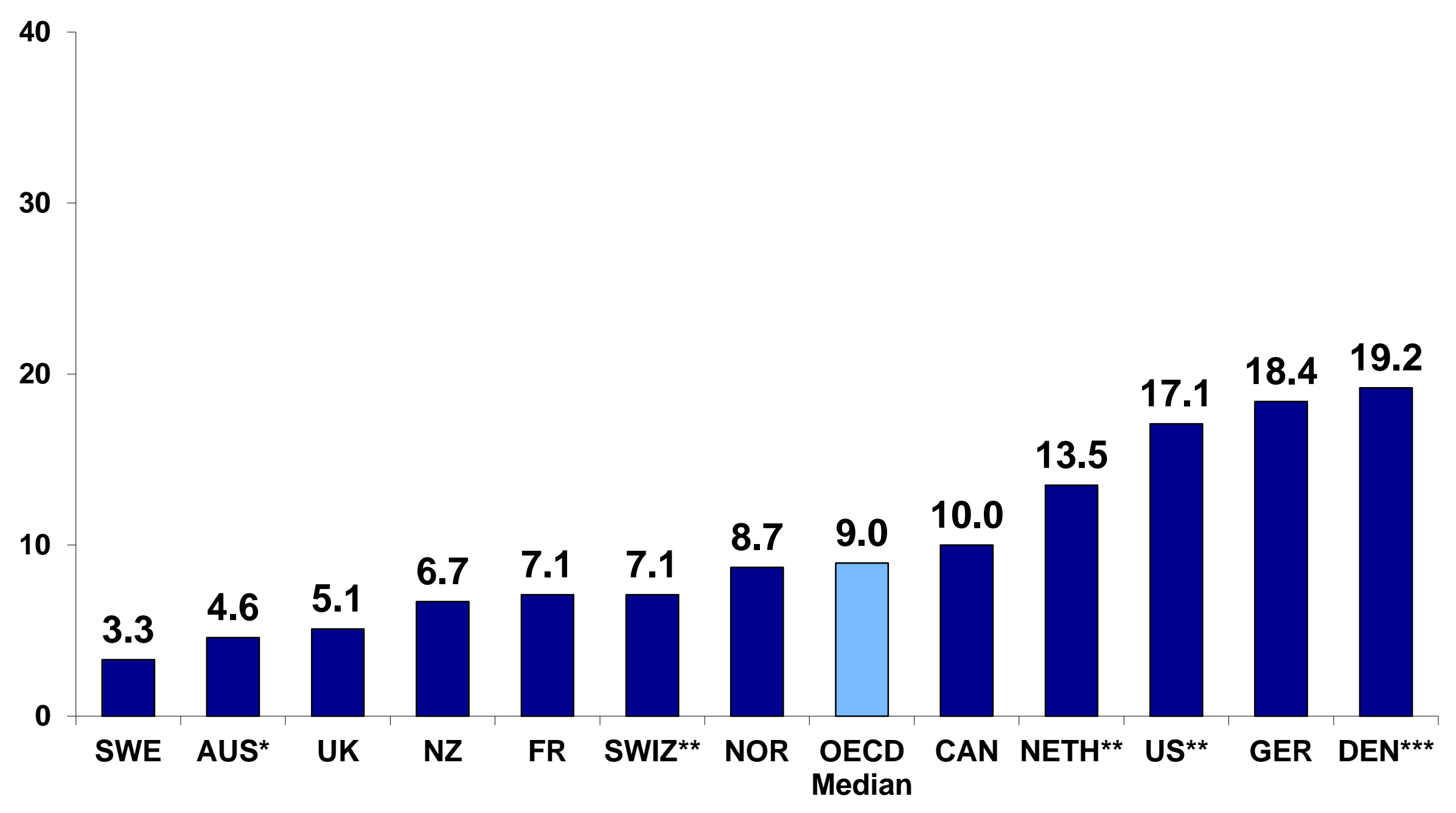




\section{Prices} FUND 


\section{Total Hospital and Physician Costs, 2013}

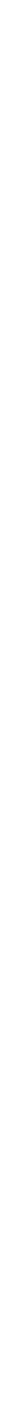

Notes: US refers to the commercial average. Appendectomy prices reflect a blend of inpatient and outpatient prices based on relative utilization in each setting.

Source: International Federation of Health Plans, 2013 Comparative Price Report. 

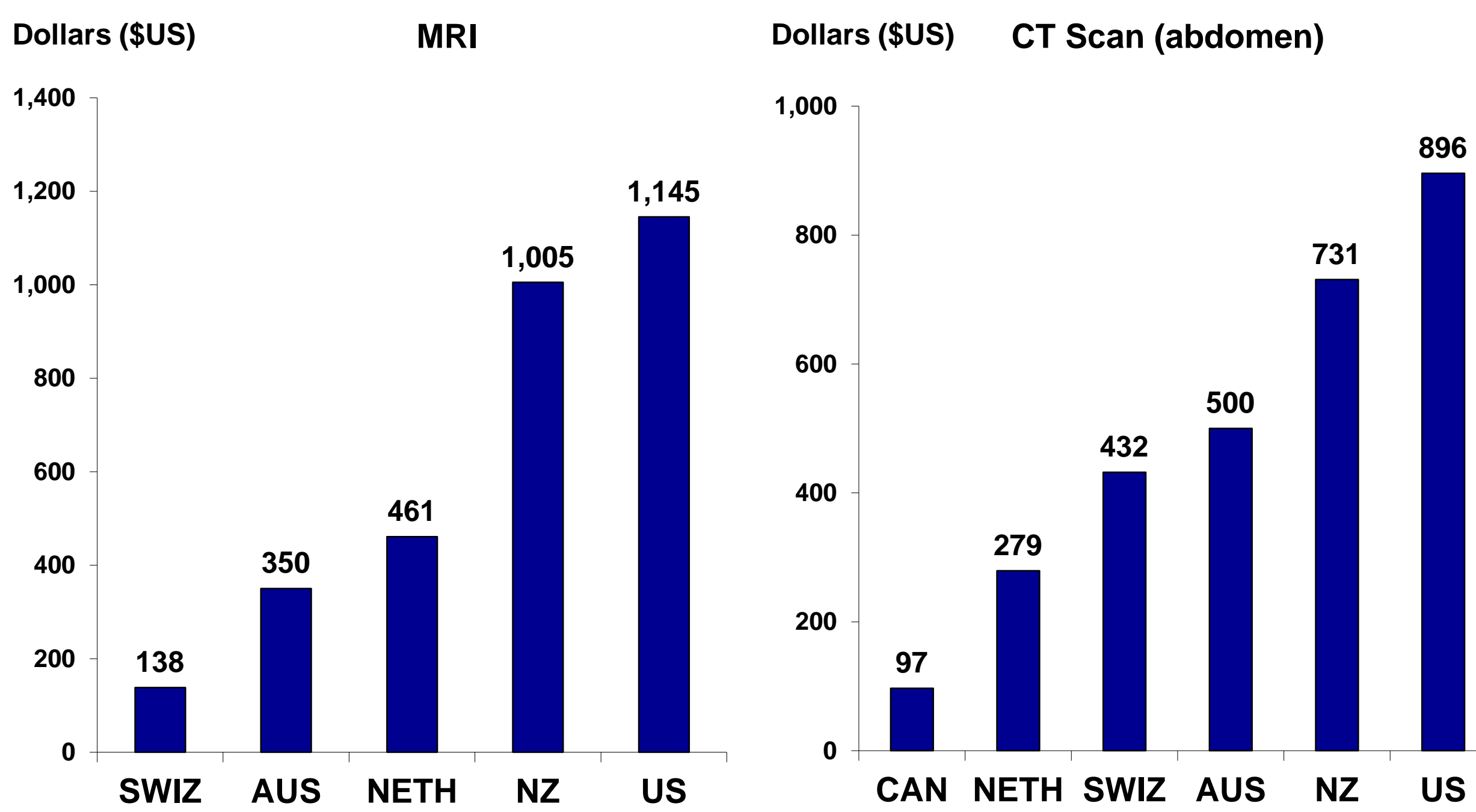

Notes: US refers to the commercial average. MRI refers to magnetic resonance imaging; CT refers to computed tomography.

Source: International Federation of Health Plans, 2013 Comparative Price Report. 


\section{Long-Term Care and Social Supports}




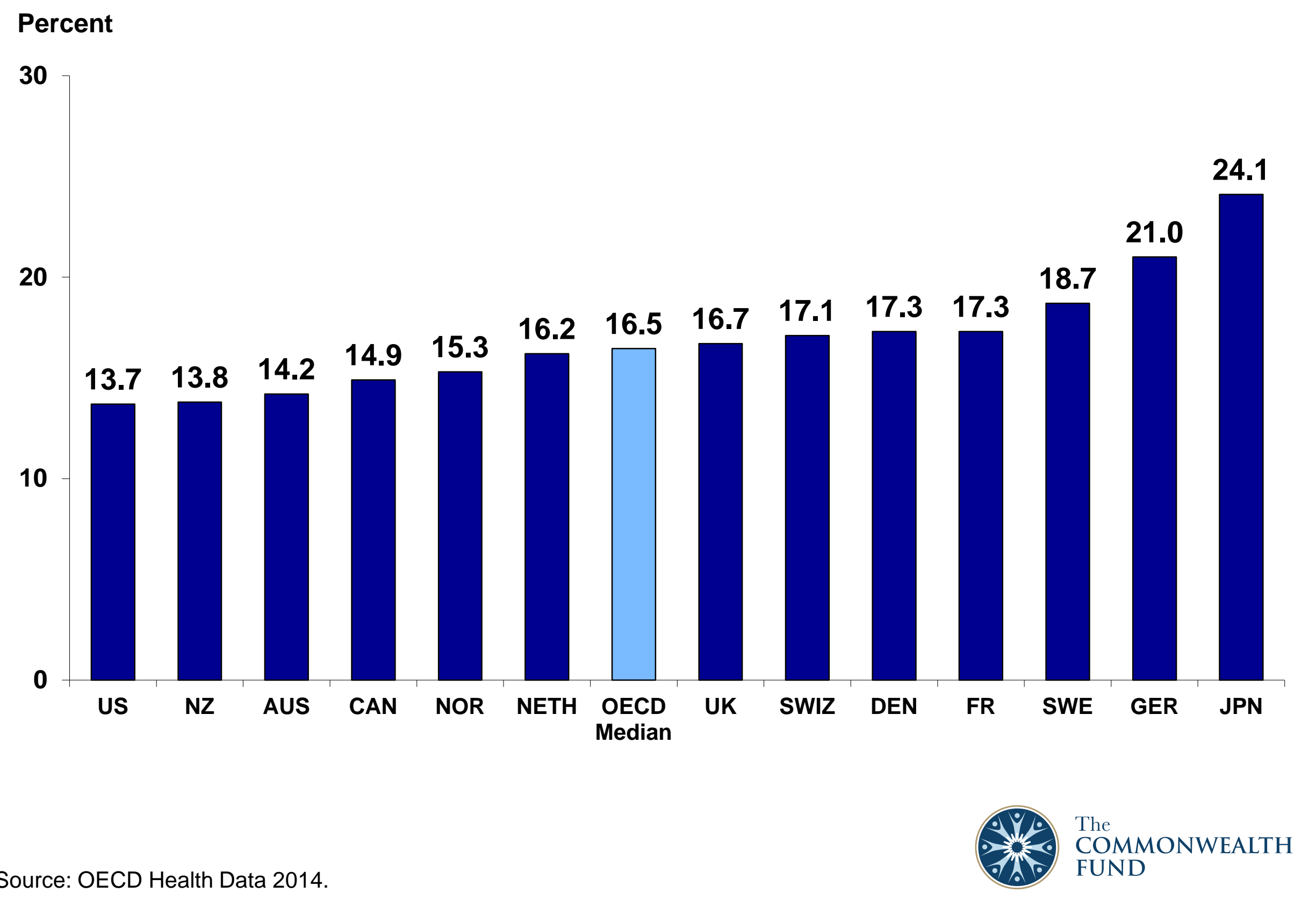




\section{Beds in Residential Long-Term Care Facilities per 100,000 Population Age 65 or Older, 2012}

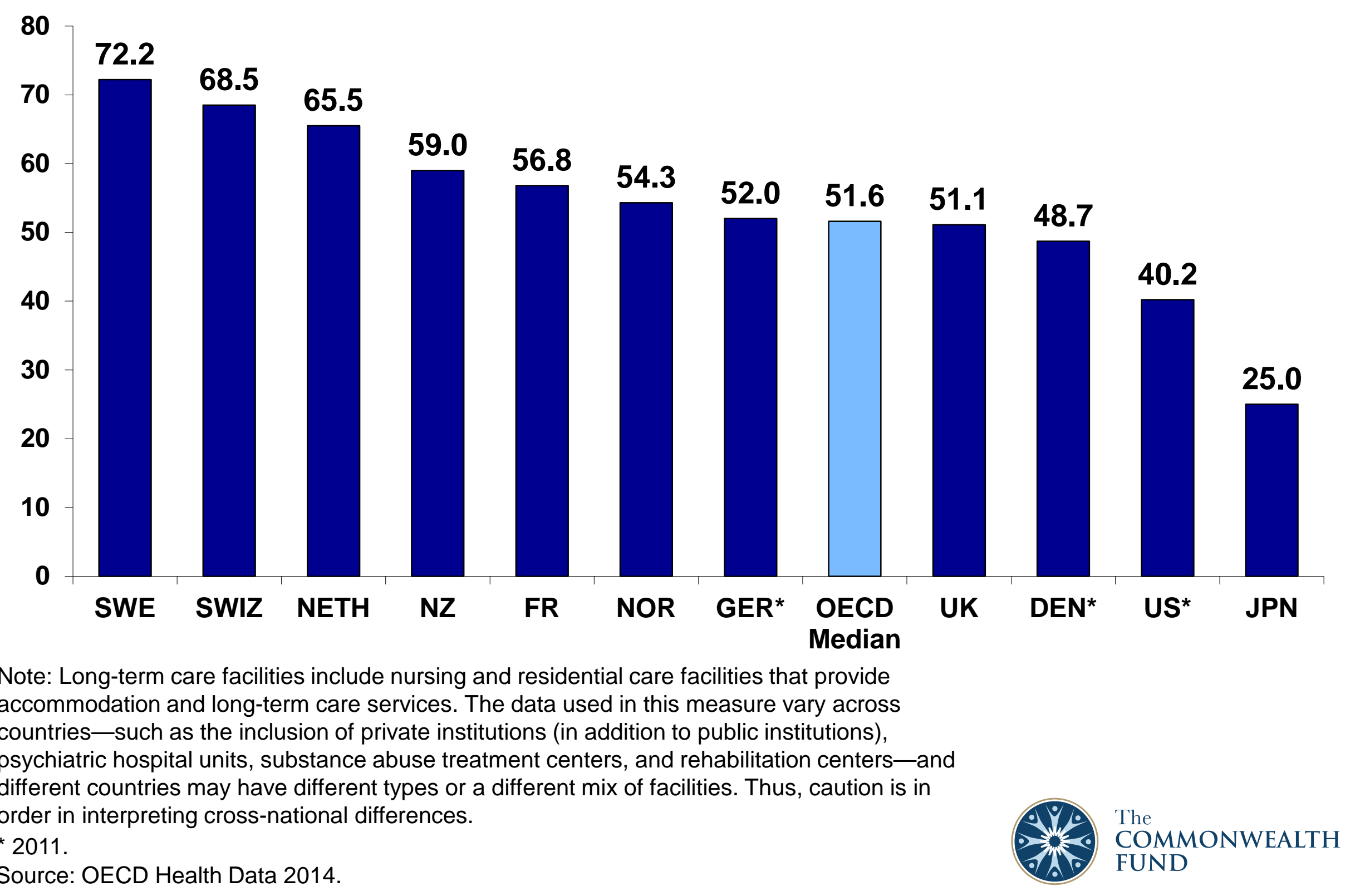




\section{Health and Social Care Spending \\ Percent of GDP}

\section{Percent}

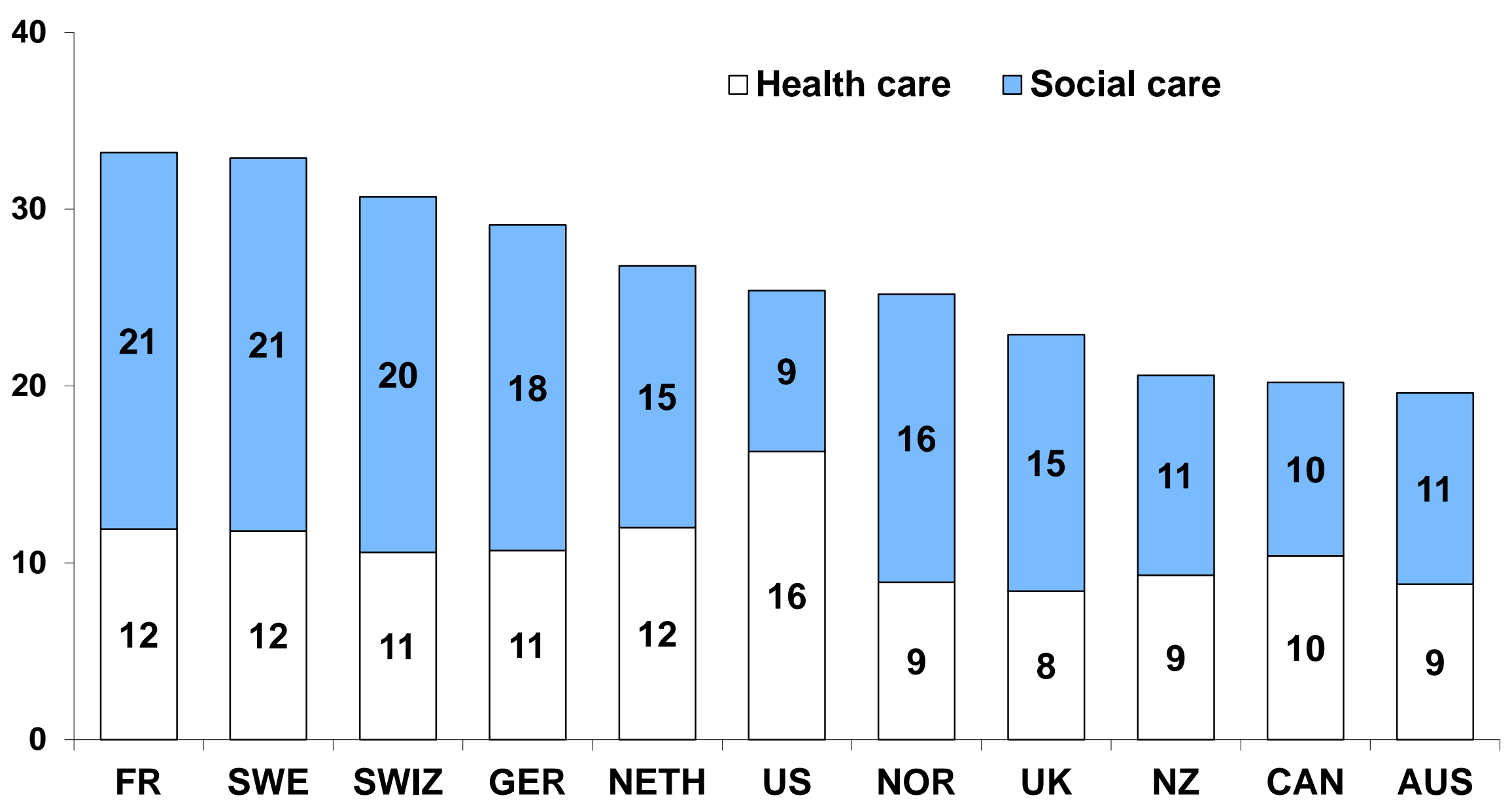

